\title{
Feedback in ESL Writing: Toward an Interactional Approach
}

\author{
Hamdollah Ravand (Corresponding author) \\ Faculty of Foreign Languages, University of Isfahan, Isfahan, Iran \\ Email:H3ravand@yhoo.com \\ Abbas Eslami Rasekh \\ Faculty of Foreign Languages, University of Isfahan, Isfahan, Iran \\ Email: Abbaseslamirasekh@yahoo.com
}

\begin{abstract}
The role of feedback on writing involves complex issues and needs to be considered within the total context in which the feedback is given. The reason studies examining feedback effects are so inconsistent may be a function of the fact that these studies consider feedback issue from a single perspective. To deal with this problem, feedback is first defined from different perspectives, then different aspects of feedback are discussed and after that a discussion of the factors that affect the influence of feedback on second language writing follows and finally a model where all the factors interact to influence feedback practices in second langue writing is presented.
\end{abstract}

Index Terms — feedback, second language writing, feedback variables, learner variables, instructional variables

\section{FEEDBACK: DEFINITIONS}

Before reviewing the research in this area, it is necessary to define two terms: errors and feedback. Our understanding of the word error itself can explain much of the disagreement that is to be found regarding its treatment. From a behaviorist viewpoint, errors were seen as bad habits which needed to be overcome through learning. For contrastive analysis, the counter part of bad habits was negative transfer. When elements from the student's L1 differed greatly with structures in the L2, the possibility of interference was seen as great (Larsen -Freeman \& Long, 1991)

With the Chomskyian inspired view of acquisition as rule driven, errors came to be seen as indicators of elements not yet fully acquired or plain lapses in performance. Put simply, errors presented a failure in linguistic competence (Svartvik, 1973). For the L2 student, errors most often represented an inadequate knowledge of rules. With the study of interlanguage, errors came to be interpreted as dialectal and not erroneous. In this continuum moving from the L1 to the target language, a student's evolving interlanguage seemed to follow a built -in syllabus that, in the absence of fossilization, would lead to something resembling the L2 without intervention (Corder 1978). In the seventies, Burt \& Kiparsky (1974) distinguished global errors from local errors. Global errors were those that showed up frequently in student production whereas local errors were one time occurrences. With more communicative views of language acquisition, errors were recognized as listener defined (Esmondson, 1993). Only those elements that caused confusion on the part of the listener warranted correction. The treatment of errors or the teacher response to errors is more commonly referred to now as feedback.

Feedback is the general heading for various techniques that are currently used in many L2 courses to respond to student writing. Feedback is defined as any procedure used to inform a learner whether an instructional response is right or wrong (Lalande, 1982).

Overall, three broad meanings of feedback have been examined (Kulhavy and Wager, 1993). First, in a motivational meaning, some feedback, such as praise, could be considered a motivator that increases a general behavior (e.g., writing or revision activities overall). This piece of the definition came from the research that tried to influence the amount of exerted effort through motivation (Brown 1932; Symonds and Chase, 1929). Second, in a reinforcement meaning, feedback may specifically reward or punish very particular prior behaviors (e.g., a particular spelling error or particular approach to a concluding paragraph). This piece of the definition came from the Law of Effect (Thorndike, 1927). Third, in an informational meaning, feedback might consist of information used by a learner to change performance in a particular direction (rather than just towards or away from a prior behavior). This piece of the definition came from information-processing theories (Pressey, 1926, 1927). In the context of writing, all three elements may be important, although the informational element is particularly important.

\section{HistoricAl PERSPECTIVE}

The importance of feedback emerged with the development of learner-centered approaches to writing instruction in North American L1 composition classes during the 1970s. The process approach gave greater attention to teacher - 
student encounters around texts and encouraged teachers to support writers through multiple drafts by providing feedback and suggesting revisions during the process of writing itself, rather than at the end of it. The form feedback took was extended beyond the teacher's marginal notes to include oral interaction involving the teacher or the students themselves. The focus moved from a concern with mechanical accuracy and control of language to a greater emphasis on the development and discovery of meaning through the experience of writing and rewriting.

Feedback practices and issues were also increasingly influenced by interactionist theories, which emphasized the significance of the individual reader rather than the dialogic nature of writing. Rather than asking students to write for an idealized general audience, the interpretation and response of a specific reader was seen as important in giving meaning to text and assisting writers to shape their texts for real people. This perspective places a high value on reader response and encourages the use of peer feedback and multiple feedback sources to provide a real rather than a visualized audience.

More recently, feedback has been seen as a key element of students' growing control over writing skills in genreoriented approaches, where sociocultural theories of scaffolded instruction and learning are important. Here feedback is important in providing students with the rhetorical choices central to new academic or professional literacy skills and as a way of assisting students in negotiating access to new knowledge and practices.

\section{FEEDBACK ASPECTS}

\section{A. Sociocultural Aspect}

Providing feedback is a an activity in which there is interaction between learners and their peers or their teacher, where the purpose is to encourage student writers' development or at least to encourage positive changes in subsequent writing. Now the question is what role this interaction might play in that development. From an interactionist point of view the answer is suggested by recent work in second language learning, which has shifted attention away from mentalist models of linguistic development to interactive ones. This has meant a shift away from terms such as linguistic competence, the linguistic environment (Long, 1996), comprehensible input, and I +1 (Krashen, 1985) -terms which emphasize learners' internal cognitive processes, to those which highlight interactions among speakers: communicative competence, negotiation of meaning, and comprehensible output. The last of these is key to the "output hypothesis", which was proposed by Swain (1985) to account for the finding that children in immersion language programs who has spent many years surrounded by meaningful L2 input and attained high levels of spoken fluency, nevertheless failed to reach similarly high levels of linguistic accuracy. Swain proposed that these learners needed not just opportunities to produce the L2, which they had in abundance, but that they also needed to be pushed to modify their speech (for example to an apparent breakdown in communication). As learners modify their linguistic output towards greater comprehensibility, their awareness of grammatical form is heightened, and they move from semantic to syntactic processing (Swain, 1995). With its obvious relevance to classroom L2 learning, the output hypothesis has provided theoretical grounding for a number of recent studies in focus of form (for example. Doughty \& Williams, 1998) and corrective feedback (for example, Lyster \& Ranta, 1997) that have reevaluated the place of grammar within communicative teaching methodologies. Although these developments have asserted a more prominent role for interaction in second language learning, they have maintained an essentially mentalist orientation in that constructs like comprehensible output are seen as external mechanisms for internal language acquisition process.

The role of interaction can also be examined from a sociocultural perspective (Lantolf, 2000). Foundational to the sociocultural theory is the developmental theory of Soviet psychologist Lev Vygotsky, who maintained that psychological phenomena must be understood not only ontogenetically (that is, as unfolding internal processes), but also in terms of their cultural and historical evolution (Kozulin, 1986). In contrast to Piaget, Vygotsky posited that speech originates in interpersonal communication during a period in which the child is wholly oriented towards the physical environment and the adults in it. Eventually, the child begins to engage in egocentric (private) speech, which is uttered aloud but not intended as communication with others. Finally, egocentric speech becomes fully internalized as inner speech, which is a cognitive tool of the mature adult (Vygotsky, 1986). Vygotsky also posited that learning is neat linear process, that it is not evolutionary but revolutionary, often occurring in fits and starts rather than clear stages (Kozulin, 1986). Moreover, learning is enhanced when the child's cognitive resources are expanded through assistance from more able others, peers or teachers. Vygotsky used the concept of "zone of proximal development" (ZPD) to describe the conceptual space that enables children to make cognitive leaps beyond their own independent problemsolving skills when they are working with an adult or more mature peer (Vygotsky, 1986). One way of conceptualizing movement within ZPD, which is relevant to discussion feedback provision, has been Wertsch's (1979a, 1979b) categorization of stages of regulation, or control over intellectual actions. Wertsch has proposed that, in the transition from interpsychological to itrapsychological activity, the learner moves from other regulation to complete self regulation. When other regulated the learner can perform with assistance from others. The learner achieves self regulation when, in the course of ZPD interactions, he can take control of external actions and is capable of independent problem solving. Because assistance in the ZPD is extended as long as other regulation persists but is removes once the learner can function independently, it has been metaphorically conceived as a form of scaffolding.

However, interactionist theories stand in sharp contrast to sociocultural theories in terms of the role assumed for the interaction. In interactionist theories of learning interaction is seen merely as a means of modifying input for the learner. 
In these theories, the learner takes from social interaction what is of benefit and processes that information alone. Long (1983) claims that through interaction, learners notice mismatches between their interlanguages and the target language. From a sociocultural perspective, in contrast, social interaction (with both humans and artifacts participating dialogically) is internalized, the external -dialogic becomes the internal-dialogic, and a socially constructed dialogic mind emerges.

\section{B. Cognitive Aspect}

Many principles of learning theory have been applied to language learning (Leki 1992; Silva 1993; Zamel 1985). One major principle has been the idea that for something to be learned it must be noticed (Ellis 1995; Schmidt 1994; Swain \&Lapkin 1995). In second language L2 acquisition studies noticing the gap has become a popular term used to explain that learners must notice the difference between their interlanguage grammar and that of the target language. The noticing hypothesis (Schmidt 1990) states that language input cannot be available for acquisition unless the learner consciously attends to it. Through noticing input becomes intake. The act of noticing and the quality of that noticing applies to L2 writing as well as to second language acquisition in general (Barestone, 1996; Cohen, 1987; Izumi \&Bigelow 2000; Polio, Fleck, \&Leder, 1998; Qi \&Lapkin, 2001; Robinson, 1995; Schmidt, 1990). The idea of noticing becomes particularly important in the process approach, where learners write multiple drafts with revisions. Teachers often intervene in this process to help learners notice problems in writing by giving different type of feedback. Research has shown that there is success in developing noticing skills (Cohen,1987; Ferris \& Roberts, 2001; Qi \&Lapkin, 2001) via feedback.

The role of feedback on writing involves complex issues and needs to be considered within the total context in which the feedback is given. Literature on variables affecting effectiveness of feedback suggests that these variables can be categorized into three groups: learner variables, feedback variables, and instructional variables. Studies examining the effectiveness of feedback have mainly looked at the issue restricting their focus on just some of the variables from the above mentioned categories. To get the full picture a feedback model that takes into account all three groups of the variables and the interaction between them is needed. First we present our proposed model and then we will examine the effect of the variables in each category and the interaction between them.

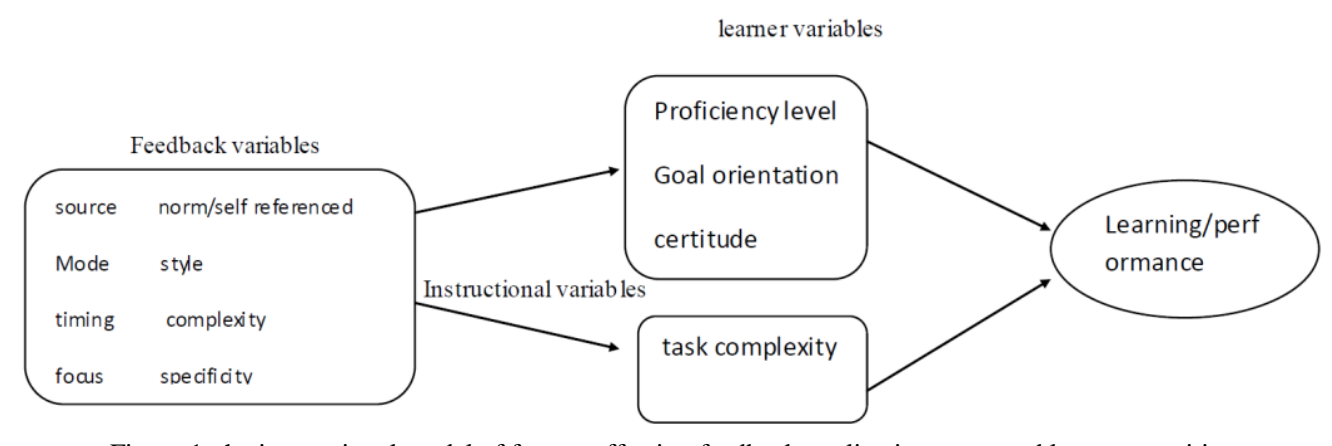

Figure 1. the interactional model of factors affecting feedback application to second language writing

\section{FEEDBACK VARIABLES}

\section{A. Source of Delivery}

One of the most common approaches for investigating the role of feedback in second language writing has been to examine the source of that feedback - that is, whether the feedback is provided by teacher or by another student.

1. Teacher feedback

Survey of students' feedback preferences indicate that ESL students greatly value teacher written feedback and consistently rate it more highly than alternative forms such as peer feedback. (Leki, 1991; Saito, 1994; Zhang, 1995). Particularly those from cultures where teachers are highly directive, generally welcome and expect teachers to notice and comment on their errors and may feel resentful if their teacher do not do so. Despite students' positive view about teachers' feedback its contribution to students' writing development is still unclear. Ferris (1997), for instance, found that although three quarters of substantive teachers' comments on drafts were used by students, only half of their revisions in response to these could be considered as improvements and a third actually made matters worse. A similarly mixed success rate emerged from Conrad and Goldstein's (1999) study of the revisions of three case study subjects. The 1960s brought a greater awareness of writing as a meaning - centered and collaborative process of generating ideas, drafting end revising. The agency of the student was increasingly valued, and concomitantly, criticisms of teacher feedback began to be voiced (Silva, 1991)

2. Peer feedback

Peer feedback has become a widespread practice in both L1 and L2 composition classrooms (F. Hyland, 2000; McGroarty \& Zhu, 1997). Some of the benefits claimed for this method include fostering a sense of audience (Keh, 1990; Lockhart\&Ng, 1994), developing students' critical reading and analysis skills(Allaei \& Connor, 1990; Mendonca 
\& Johndon, 1994), receiving scaffolded support (Guerrero \& Villamil, 1994,2000), as well as gaining a deeper understanding of the communicative nature of the writing process (Allaei \& Connor, 1990; Porto, 2001) -all within a learner- centered environment that increases student motivation and independence (Chaudron, 1984) and does not penalize the students for errors (Diaz, 1991). By using peer revision, students receive immediate feedback, instead of days or weeks later, when solving their writing problems is no longer such a pressing matter (Frankenberg-Garcia, 1999). However, as is the case with teacher feedback, peer feedback has also had its fair share of criticisms. Stanley (1992), for example, reports that students, who are used to reading professionally - crafted prose, are not sufficiently critical of their peers' work, as they read for global meaning, use their schemata to fill in cohesive gaps, and infer information even when the writer has failed to prove the necessary background to authorize such as inferences. Jacobs (1989) similarly contends that students lack the necessary sophistication and objectivity needed to respond to a piece of work. Other students may become defensive when receiving peer feedback (Amores, 1997), or they may feel that their peers are not qualified to critique their work and hence distrust or ignore their comments (Mangelsdorf, 1992; Nelson\& Carson, 1998; Nelson \& Murphy, 1993; Sengupta, 1998)

Feedback is a complex process, and any evaluation of the relative efficacy of feedback needs to take other variables in the same category and other categories of the proposed model into account. For example regarding the efficacy of each feedback source among other variables, the pedagogical context, individual preferences, and the assignment at hand (Ferris, 1997; Goldstein, 2001) should be taken into account. For example, in single -draft classrooms stressing grammatical accuracy, it is not surprising that students may pay little attention to teacher feedback: the essay, the final product, is submitted for a grade and there are no further opportunities for revision. However, in multiple -draft classrooms, students may take teacher feedback more seriously because it enables them to rethink and revise their assays (and thus perhaps raise their grades) (Ferris, 1995). Due to the interaction of feedback variables with each other and with variables from other categories "any effort to establish the superiority of one over the other is.... Misguided" (Tsui\& Ng, 2000).

However, we still do not have a solid understanding of the relationship between feedback source and writing quality. One reason can be the confounding interaction of the variables involved in each situation such as those concerning feedback mode, timing of feedback, and the type of assessment procedure researcher used to assess the impact of feedback source.

\section{B. Feedback Mode}

As suggested above any comparison of teacher written feedback and peer oral feedback will be problematic in that it fails to tease apart two important variables, feedback source and feedback mode.

Literature on feedback have mainly investigated the efficacy of feedback delivered orally; canned (audiotaped) (Anson, 1997; Boswood \& Dwyer, 1995; Cryer \& Kaikumba, 1987; Johnson, 1999; McAlpine, 1989; Yarbo \& Angentivine, 1982) and writing conferences (Keh, 1990; Goldstein \& Conrad, 1990; Patthey-Chavez \& Ferris, 1997) among others) and written teacher feedback. Johnson (1999) claimed that recording comments about a student's writing onto a tape allows teachers to provide more detailed comments as they are not constrained by the space limitations involved in writing comments in margins, more comprehensible comments, and more personable comments as they are no longer impersonal graders but rather writing coaches.

More commonly, researchers have made the argument for oral feedback by advocating the use of one to one teacher student conferences. Such researchers have asserted that conferences are more effective than traditional written methods because, in conferences, the teacher - reader is a live audience, and thus is able to ask for clarification, check the comprehensibility of oral comments made, help the writer sort through problems, and assist the student in decision making (Keh, 1990). Other researchers have invoked Vygotsky's theories on social interaction and scaffolded help(e.g., Patthey -Chavez \&Ferris, 1997; villamil\& Guerrero,1996). According to Vygotsky (1978), knowledge is social in nature; thus, the process of interacting with a more knowledgeable other (e.g., the teacher) allows the learner to internalize both linguistic and cognitive abilities, including writing skills (Hedgcock \&Lefkowita, 1992; Lockhart\&Ng, 1995a). Finally, it has been noted that in oral feedback sessions, nonverbal communication, such as differences in intonation and facial expressions, can serve to mitigate criticism and thus encourage a more collaborative stance between the reviewer and the writer. Although many studies found the positive effect of different modes of feedback, the findings are not conclusive, and more studies are needed to compare the effect of different modes and control for the effect of the interaction between the variables in the proposed model.

Recently, researchers have also begun to investigate the effectiveness of online electronic feedback (e-feedback) (Tuzi, 2004). E-feedback, which possesses characteristics of both oral interaction (such as an informal, conversational tone) and written (such as the fact that the feedback must be typed, the lack of nonverbal and intonational cues, and the distance between rediever), refers to forms of response provided in written form and transmitted via the web. MacLeod (1999) argued that because the reviewers do not have to face the writers while proviking feedback, they can provide more honest feedback. In a similar vein, DiGiovanni and Nagaswami 2001) noted that since students do not have to be concerned with responding immediately to the writer in real time, they can reflect on their ideas rehearse their response, and respond at their own pace.

\section{Feedback Focus}


Form-focused and content focused feedback

'Fluency first' approaches which prioritize the development of the student's voice over grammatical accuracy have argued against providing feedback on form.

Truscott (1996), for example, has argued that feedback on form is ineffective, time -absorbing, and potentially harmful in that it diverts attention from organization, and logical development of ideas, deflates student motivation, and encourages the writer, now fearful of the red pen, to rely on simpler, safer sentence structures. Criticizing Truscott, Ferris (1999) claimed that Truscott ignored the mounting research evidence supporting the use of certain kinds of grammar correction, and that and that Truscott instead based his conclusions on limited, dated, incomplete, and inconclusive evidence. Ferris (1995) found that students in single draft classrooms expressed a preference for form focused feedback and students in multiple draft classrooms indicating that they valued content focused feedback. This finding is similar to that reported in Hedgcock and Lefkowits $(1994,1996)$, who found that ESL students in process oriented classrooms where students were required to submit multiple drafts valued both meaning level and surface level feedback, while FL students in product oriented classrooms (where the students typically submitted only one draft of a given assignment paid more attention to form. However, the majority of L2 writing studies investigating feedback focus have not reported results which are strongly supportive of feedback on form.(e.g., Frantzen, 1995; Kepner,1991; Polio et al., 1998; Semke, 1984; Sheppard, 1992).

In a form/content comparison study, Fazio (2001) compared the effects of three types of feedback content only, form only, and a combination of form focused and content focused feedback on grammatical accuracy (subject verb agreement and noun adjective agreement) of journals produced by native and non native speakers of French. Fazio found that neither the native nor the non native speakers in any of the three conditions made any significant changes in the number of agreement errors over four the months. Some researchers believe that discussions of feedback should go beyond focus on form or content (Ferris, Pezone, Tade,\&Tniti, 1997), and rather we should know that both focus on form and focus on content have got a place in L2 writing classrooms but the timing (when to provide feedback on form and when to provide feedback on content) of provision of each type should be different. For example, it has been argued that form and content feedback should not be used simultaneously, as students may not know which one deserves higher priority (Zamel, 1985). Instead teachers are encouraged to provide feedback on the content of the students' writings first, saving comments on form for later drafts, when students are in the final stages of polishing their drafts.

\section{Feedback Style}

In addition to the feedback variables discussed so far, feedback style is a strand in feedback research. Feedback style refers to the linguistic and pragmatic characteristics of the feedback, including the illocutionary force of feedback (e.g., whether teacher uses questions, suggestions, or commands) and the explicitness of the feedback(e.g., whether codes or explicit corrections are provided). One in which feedback style has been addressed is to examine the illocutionary force of feedback. Researchers investigating this issue have sought to determine which feature(s) best promote student noticing and use of feedback. For example, it may be the case that students may not perceive the corrective intent of a question; likewise, they may be more inclined to revise their writing after having received a command rather than a politely hedged request.

To examine the issue, Ferris (1997) examined the textual and pragmatic characteristics of one teacher's written feedback to a class of freshmen ESL university composition students. He found that the students' revisions in response to the teacher's questions were often unsuccessful, and he cautioned teachers to be careful when using questions, as students may not be able to glean from the question what change they should make or exactly how to go about making that change.

Directness is another way in which feedback style has been investigated. This broad category includes studies examining the differential effect of explicit corrections, implicit feedback (such as codes or question marks which indirectly indicate that the learner's text was in some way problematic), and reformulations on students' writing. Lalande (1982) found that coded feedback is superior to explicit feedback, as the former encourages the students to take an active problem solving role in correcting their own errors. Rob,Ross and Shortreed (1986) found that the assumption underlying overt correction - that more correction results in more accuracy -was nor convincingly demonstrated. Ferris and Roberts (2001) reached a similar conclusion. In their study they found that even though the feedback group outperformed the non feedback group, there were no significant difference between groups receiving coded feedback and those with non coded feedback, leading them to conclude that more explicit feedback is not necessarily beneficial.

Reformulation is another area of investigation related to feedback explicitness. There have been few empirical studies which have compared reformulated feedback with other types of feedback, and those that have done so have either been small scale descriptive studies studies (e.g., Allwright et al., 1988; Cohen, 1983a, 1983b, 1989; Sanaoui, 1984) or have found no significant difference Mantello, 1997 noted that reformulated feedback seemed to be more appropriate for advanced students in her study. Coded feedback, inasmuch as it identified the exact location and nature of the error, was reported to be more beneficial for the weaker students.

\section{E. Feedback Specificity}

Feedback specificity is defined as the level of information presented in feedback messages (Goodman, Wood, \& Hendrickx, 2004). Several researchers have reported that feedback is significantly more effective when it provides 
details of how to improve the answer rather than just indicating whether the student's work is correct or not (e.g., Bangert-Drowns et al., 1991; Pridemore \& Klein, 1995). Feedback lacking in specificity may cause students to view it as useless, frustrating, or both (Williams, 1997). It can also lead to uncertainty about how to respond to the feedback (Fedor, 1991) and may require greater information-processing activity on the part of the learner to understand the intended message (Bangert-Drowns et al., 1991). Uncertainty and cognitive load can lead to lower levels of learning (Kluger \& DeNisi, 1996; Sweller et al., 1998) or even reduced motivation to respond to the feedback (Ashford, 1986; Corno \& Snow 1986).

\section{F. Feedback Complexity}

In studying the role of feedback a related dimension to consider is length or complexity of the information. Schimmel (1983) performed a meta-analysis on feedback as used in computer based instruction (CBI) and programmed (scripted) instruction. He analyzed the results from 15 experimental studies and found that the amount of information (i.e., feedback complexity) was not significantly related to feedback effects. Kulhavy, White, Topp, Chan, and Adams (1985) similarly examined the feedback complexity issue. The main finding was that complexity of feedback was inversely related to both ability to correct errors and learning efficiency (i.e., the ratio of feedback study time to posttest score). Specifically, Kulhavy et al. showed that more complex versions of feedback had a small effect on students' ability to correct their own errors, and the least complex feedback (i.e., correct answer) demonstrated greater learner benefits in terms of efficiency and outcome than complex feedback.

\section{G. Feedback Timing}

1. Delayed vs immediate

Similar to the previously mentioned feedback variables (e.g., complexity and specificity), there are also conflicting results in the literature relating to the timing of feedback Some researchers have argued for immediate feedback as a means to prevent errors being encoded into memory, whereas others have argued that delayed feedback reduces proactive interference, thus allowing the initial error to be forgotten and the correct information to be encoded with no interference (for more on this debate, see Kulhavy \& Anderson, 1972). The superiority of delayed feedback, referred to as the delay-retention effect (DRE), was supported in a series of experiments by Anderson and colleagues (e.g., Kulhavy \& Anderson, 1972; Surber \& Anderson, 1975), comparing the accuracy of responses on a retention test with the accuracy of responses on an initial test. Schroth (1992) presented the results from an experiment that investigated the effects of delayed feedback and type of verbal feedback on transfer using a concept formation task. The finding is that although delayed feedback slowed the rate of initial learning, it facilitated transfer after the delay.

Supporters of immediate feedback theorize that the earlier corrective information is provided, the more likely it is that efficient retention will result (Phye \& Andre, 1989). The superiority of immediate over delayed feedback has been demonstrated for the acquisition of verbal materials, procedural skills, and some motor skills (Anderson, Magill, \& Sekiya, 2001; Brosvic \& Cohen, 1988; Corbett \& Anderson, 1989, 2001; Dihoff, Brosvic, Epstein, \& Cook, 2003). Corbett and Anderson (2001) have been using immediate feedback successfully in their programming and mathematics tutors for almost two decades For instance, they used their ACT Programming Tutor to examine differential timing effects on students' learning. This study demonstrated that immediate error feedback helped with immediate learning. A preliminary conclusion derived from both the Schroth (1992) and Corbett and Anderson (2001) findings is that delayed feedback may be superior for promoting transfer of learning, especially in relation to concept-formation tasks, whereas immediate feedback may be more efficient, particularly in the short run and for procedural skills (i.e., programming and mathematics). Mathan and Koedinger (2002) reviewed various studies on the timing of feedback and concluded that the effectiveness of feedback depends not on the main effect of timing but on the nature of the task and the capability of the learner. Another variable reported to have such interaction with feedback timing concerns task difficulty. That is, if the task is difficult, then immediate feedback is beneficial, but if the task is easy, then delayed feedback may be preferable (Clariana, 1999). This is similar to the ideas presented earlier in the Formative Feedback as Scaffolding subsection.

\section{H. Normative Feedback}

According to research cited in Kluger and DeNisi (1996), when feedback is provided to students in a norm referenced manner that compares the individual's performance with that of others, people who perform poorly tend to attribute their failures to lack of ability, expect to perform poorly in the future, and demonstrate decreased motivation on subsequent tasks. McColskey and Leary (1985) examined the hypothesis that the harmful effects of failure might be lessened when failure is expressed in self-referenced terms - that is, relative to the learner's known level of ability as assessed by other measures. They found that, compared to norm referenced feedback, self-referenced feedback resulted in higher expectancies regarding future performance and increased attributions to effort (e.g., "I succeeded because I worked really hard"). Attributions to ability (e.g., "I succeeded because I'm smart") were not affected. The main implication is that low-achieving students should not receive normative feedback but should instead receive selfreferenced feedback - focusing their attention on their own progress.

\section{LEARNER VARIABLES}




\section{A. Learner Level}

As alluded to in the Timing subsection of this article, some research has suggested that low-achieving students may benefit from immediate feedback, whereas high-achieving students may prefer or benefit from delayed feedback (Gaynor, 1981; Roper, 1977). Furthermore, when testing different types of feedback, Clariana (1990) has argued that low-ability students benefit from receipt of correct response feedback more than from try again feedback. Hanna (1976) also examined student performance in relation to different feedback conditions: verification, elaboration, and no feedback. The verification feedback condition produced the highest scores for high-ability students and elaborated feedback produced the highest scores for low-ability students. There were no significant differences between verification and elaborated feedback for middle-ability students, but both of these types of feedback were superior to no feedback.

\section{B. Response Certitude}

Kulhavy and Stock (1989) examined feedback and response certitude issues from an information-processing perspective. That is, they had students provide confidence judgments ("response certitude" ratings) following each response to various tasks. They hypothesized that when students are certain their answer is correct, they will spend little time analyzing feedback, and when students are certain their answer is incorrect, they will spend more time reviewing feedback. The implications of this are straightforward; that is, provide more elaborated feedback for students who are more certain that their answer is wrong and deliver more constrained feedback for those with high certitude of correct answers. Although their own research supported their hypotheses, other studies did not replicate the findings. For instance, Mory (1994) tried to replicate the response certitude findings and found that although there were differences in the amount of feedback study time, there was no significant learning effect for feedback tailored to response certitude and correctness.

\section{Goal Orientation}

Davis, Carson, Ammeter, and Treadway (2005) reported the results of a study testing the relationship between goal orientation and feedback specificity on performance using a management decision-making task. In short, they found that feedback specificity (low, moderate, and high levels) had a significant influence on performance for individuals who were low on learning orientation (i.e., high feedback specificity was better for learners with low learning orientation). They also reported a significant influence of feedback specificity on performance for persons high in performance orientation (i.e., this group also benefited from more specific feedback). The findings support the general positive effects of feedback on performance and suggest the use of more specific feedback for learners with either highperformance or low-learning goal orientations.

\section{INSTRUCTIONAL VARIABLES}

\section{Task complexity}

Kluger and DeNisi (1996) examined and reported on the effects of feedback interventions (FIs) on performance from multiple perspectives and spanning decades of research-back to Thorndike's classic research in the early 1900s. The of results from Kluger and DeNisi's (1996) large metaanalysis of FI studies suggest that FIs in the context of complex tasks yield weaker effects than for simpler tasks. Mason and Bruning (2001) reviewed the literature on feedback in relation to student achievement level, task complexity, timing of feedback, and prior knowledge. The general recommendation they have drawn from the framework is that immediate feedback for students with low achievement levels in the context of either simple (lower level) or complex (higher level) tasks is superior to delayed feedback, whereas delayed feedback is suggested for students with high achievement levels, especially for complex tasks.

\section{CONCLUSION}

As Shute (2008) suggests the reason studies examining formative feedback effects are so inconsistent may be a function of individual differences among motivational prerequisites (e.g., intrinsic motivation, beliefs, need for academic achievement, academic self-efficacy, and metacognitive skills). Another reason may be the type of assessment procedure researcher used to assess the impact of feedback source. Still another more important reason be the interactions among task characteristics, instructional contexts, and student characteristics that potentially mediate feedback effects that remains uninvestigated.

In general, and as suggested by Schwartz and White (2000) cited earlier, we need to continue taking a multidimensional view of feedback where situational and individual characteristics of the instructional context and learner are considered along with the nature and quality of a feedback message. Narciss and Huth (2004) noted, that function, content, and mode of feedback presentation are important facets and should be considered separately as well as interactively with learner characteristics and instructional variables. And as Shute (2008) suggests there is no "best" type of feedback for all learners and learning outcomes.

\section{REFERENCES}


[1] Allaei, S. K., \& Connor, U. (1990). Using performative assessment instruments with ESL student writers. In L. Hamp-Lyons (Ed.), Assessing second language writing in academic contexts (pp. 227-240). Norwood, NJ: Ablex.

[2] Amores, M. 3. (1997). A new perspective on peer-editing. Foreign Language Annals, 30(4), 513-523.

[3] Anson, C. M. (1997). In our own voices: Using recorded commentary to respond to writing. In P. Elbow \& M. D. Sorcinelli (Eds.), Writing to learn: Strategies for assigning and responding to writing across the disciplines (pp. 105- 115). San Francisco, CA: Jossey-Bass.

[4] Batestone, R. (1996). Noticing. ELT Journal, 50, 273.

[5] Burt, M.K., \&C. Kiparsky, 1974: "Global and Local Mistakes," in J. Schumann and N. Stenson (ed), New Frontiers in the Second Language Learning, Rowley, MA: Newbury House, pp.71-80

[6] Boswood, T., \& Dwyer, R. (1995/96). From marking to feedback: Audio-taped responses to student writing. TESOL Journal, $5(2), 20-23$

[7] Brown, F. J. (1932). Knowledge of results as an incentive in school room practice. Journal of Educational Psychology, 23(7), 532-552.

[8] Chaudron, C. (1984). The effects of feedback on students' composition revisions. RELC Journal, 15, 1-14.

[9] Clariana, R. B. (1990). A comparison of answer-until-correct feedback and knowledge of-correct-Response feedback under two conditions of contextualization. Journal of n Computer-Based Instruction, 17(4), 125-129.

[10] Cohen, A. D.(1987). Student processing of feedback on their compositions. In A. Wendon and R. Ribu (Eds.), Learner strategies in language learning (57- 69) Prentice Hall.

[11] Conrad, S., \& Goldstein, L. (1999). ESL student revision after teacher-written comments: Text, contexts, and individuals. Journal of Second Language Writing, 8, 147-180.

[12] Corder, S.P., (1978). "Language-learner language," in J. P. Richards (ed), Understanding Second and Foreign Language Learning: Issues and Approaches, Rowley, MA: Newbury House, pp.71-93

[13] Cryer, P., \& Kaikumba, N. (1987). Audio-cassette tape as a means of giving feedback non written work. Assessment and Evaluation in Higher Education, 12, 148-153.

[14] Diaz, D. (1991). Writing, collaborative learning, and community. College ESL, 1(1), 19- 24

[15] DiGiovanni, E., \& Nagaswarni, G. (2001). Online peer review: An alternative to face-to f ace? ELT Journal, 55(3), $263-272$.

[16] Doughty, C., \& Williams, J. (Eds.). (1998). Focus on form in classroom second language acquisition. Cambridge, UK: Cambridge University Press.

[17] Edmondson, W. (1993). "What Do Learners Get out of Teachers' Treatment of Errors?" Paper read at the $10^{\text {th }}$ AILA Congress, Amsterdam.

[18] Ellis, R. (1995). Interpretation tasks for grammar teaching. TESOL Quarterly, 29(1), 87- 105.

[19] Fazio, L. (2001). The effect of corrections and commentaries on the journal writing accuracy of minority- and majoritylanguage students. Journal of Second Language Writing, 10(4), 235-249.

[20] Ferris, D. R. (1995). Student reactions to teacher response in multiple-draft composition classrooms. TESOL Quarterly, 29(1), 35-51.

[21] Ferris, D. R. (1997). The influence of teacher commentary on student revision. TESOL Quarterly, 31, 3 15-339.

[22] Ferris, D. R. (1999). The case for grammar correction in L2 writing classes: A response to Truscott (1996). Journal of Second Language Writing, 8(1), 1-11.

[23] Ferris, D. R., Pezone, S., Tade, C. R., \& Tinti, S. (1997). Teacher commentary on student writing: Descriptions and implications. Journal of Second Language Writing, 6(2), 155-182.

[24] Ferris, D., \& Roberts, B. (2001). Error feedback in L2 writing classes: How explicit does it need to be? Journal of Second Language Writing, 10(3), 16 1-184.

[25] Frankenberg-Garcia, A. (1999). Providing student writers with pre-text feedback. ELT Journal, 53(2), 100-106.

[26] Frantzen, D. (1995). The effects of grammar supplementation on written accuracy in an intermediate Spanish content course. The Modern Language Journal, 79(3), 329- 344.

[27] Gaynor, P. (1981). The effect of feedback delay on retention of computer-based mathematical material. Journal of ComputerBased Instruction, 8(2), 28-34.

[28] Goldstein, L. M. (2001). For Kyla: What does the research say about responding to ESL writers? In T. Silva \& P. K. Matsuda (Eds.), On second language writing (pp. 73- 89. Mahwah. NJ: Lawrence Eribaum Associates.

[29] Goldstein, L. M., \& Conrad, S. (1990). Student input and the negotiation of meaning in ESL writing conferences. TESOL Quarterly, 24(3), 443- 460.

[30] Guerrero, M. C. M. de \& Villarnil, 0. S. (1994). Social-cognitive dimensions of interaction in L2 peer revision. The Modern Language Journal, 78(4), 4 84-496.

[31] Guerrero, M. C. M. de \& Villamil, 0. S. (2000). Activating the ZPD: Mutual scaffolding in L2 peer revision. The Modern Language Journal, 84(1), 51-68.

[32] Hanna, G. S. (1976). Effects of total and partial feedback in multiple-choice testing upon learning. Journal of Educational Research, 69(5), 202-205.

[33] Hedgcock, 3. \& Lefkowitz, N. (1992). Collaborative oral/aural revision in foreign language writing instruction. Journal of Second Language Writing, 1(3), 255-276.

[34] Hedgcock, J., \& Lefkowitz, N. (1994). Feedback on feedback: Assessing learner receptivity to teacher response in L2 composing. Journal of Second Language Writing, 3(2), 141-163.

[35] Hedgcock, J., \& Lefkowitz, N. (1996). Some input on input: Two analyses of student response to expert feedback in L2 writing. The Modern Language Journal, 80(3), 287-308.

[36] Hyland, F. (2000). ESL writers and feedback: Giving more autonomy to students. Language Teaching Research, 4(1), 33-54.

[37] IzumiS., \& Bigelow, M. (2000). Does output promote noticing and second language acquisition? TESOL Quarterly. 34 (2), 239-278.

[38] Krashen, S. (1985). The input hypothesis: Issues and implications. London and New York: Longman. 
[39] Jacobs, G. M. (1989). Miscorrection in peer feedback in writing class. RELC Journal, 20, 68-76.

[40] Johanson, R. (1999). Rethinking the red ink: Audio-feedback in the ESL writing classroom. Texas Papers in Foreign Language Education, 41(1), 3 1- 38.

[41] Keh, C. L. (1990). Feedback in the writing process: A model and methods for implementation. ELT Journal, 44(4), 294-304.

[42] Kepner, C. (1991). An experiment in the relationship of types of written feedback in the development of second-language writing skills. The Modern Language Journal, 75(3), 305-3 13.

[43] Kozulin, A. (1986). Vygotsky in context. Introduction to L. Vygotsky, Thought and language Cambridge, MA: The MIT Press.

[44] Kulhavy, R. W., \& Stock, W. (1989). Feedback in written instruction: The place of response certitude. Educational Psychology Review, 1(4), 279-308.

[45] Kulhavy, R. W., \& Wager, W. (1993). Feedback in programmed instruction: Historical context and implications for practice. In J. V. Dempsey, \& G. C. Sales (Eds.), Interactive instruction and feedback (pp. 3-20). Englewood Cliffs, NJ: Educational Technology.

[46] Lantolf, J. (Ed.). (2000). Sociocultural theory and second language learning. New York: Oxford University Press.

[47] Lalande, J. (1982). "Reducing composition errors : an experiment," Modern Language Journal 66,pp. 140-149

[48] Larsen Freeman, D. and M. H. Long, (1991). An Introduction to Second Language Acquisition Research. New York: Longman

[49] Leki, 1. (1991). The preferences of ESL students for error correction in college- level writing classes. Foreign Language Annals, 24, 203-218.

[50] Leki, I. (1992). Understanding ESL writers. Portsmouth, NH: Boynton/Cook Publishers.

[51] Lockhart, C., \& Ng, P. (1995a). Analyzing talk in ESL peer response groups: Stances, functions, and content. Language Learning, 45(4), 605-655.

[52] Long, M. (1996). The role of the linguistic environment in second language acquisition. In W. Ritchie \& T. Bhatia (Eds.), Handbook of second Language acquisition (pp. 413-468). New York: Academic Press.

[53] Lyster, R. \& Ranta, L. (1997). Corrective feedback and learner uptake: Negotiation of form in communicative classrooms. Studies in Second Language Acquisition, 19, 37-66.

[54] McAlpine, L. (1989). Teacher-as-reader: Oral feedback on ESL student writing. TESL Canada Journal, 7(1), 62-67.

[55] Mangelsdorf, K. (1992). Peer reviews in the ESL composition classroom: What do the students think? ELT Journal, 46(3), $274-$ 283.

[56] Mason, B. J., \& Bruning, R. (2001). Providing feedback in computer-based instruction: What the research tells us. Center for Instructional Innovation, University of Nebraska-Lincoln: 14. Retrieved June 1, 2006, from http://dwb.unl.edu/Edit/MB/ MasonBruning.html

[57] McGroarty, M. E., \& Zhu, W. (1997). Triangulation in classroom research: A study of peer revision. Language Learning, 47(1), $1-43$.

[58] Mendonça, C. 0., \& Johnson, K. E. (1994). Peer review negotiations: Revision activities in ESL writing instruction. TESOL Quarterly, 28(4), 745- 768.

[59] Mory, E. H. (1994). Adaptive feedback in computer-based instruction: Effects of response certitude on performance, feedbackstudy time, and efficiency. Journal of Educational Computing Research, 11(3), 263-290.

[60] Narciss, S., \& Huth, K. (2004). How to design informative tutoring feedback for multimedia learning. In H. M. Niegemann, D. Leutner, \& R. Brunken (Ed.), Instructional design for multimedia learning (pp. 181-195). Munster, NY: Waxmann.

[61] Nelson, G., \& Carson, 3. G. (1998). ESL students' perceptions of effectiveness in peer response groups. Journal of Second Language Writing, 7(2), 113-131.

[62] Nelson, G., \& Murphy, M. (1993). Peer response groups: Do L2 writers use peer comments in revising their drafts? TESOL Quarterly, 27(1), 135-141.

[63] Patthey-Chavez, G. G., \& Ferris, D. R. (1997). Writing conferences and the weaving of multi-voiced texts in college composition. Research in the Teaching of English, 31(1), 51-90.

[64] Polio, C., Fleck, C., \& Leder, N., (1998). “If I only had more time:” ESL learners' changes in linguistic accuracy on essay revisions. Journal of Second Language Writing,(1), 43-68.

[65] Porto, M. (2001). Cooperative writing response groups and self-evaluation. ELT Journal, 55(1), 38-46.

[66] Pressey, S. L. (1926). A simple device which gives tests and scores - and teaches. School and Society, 23,373-376.

[67] Pressey, S. L. (1927). A machine for automatic teaching of drill material. School and Society, 25, 549-552.

[68] Qi, D.S., \& Lapkin, S. (2001). Exploring the role of noticing in a three-stage second language writing task. Journal of Second Language Writing, 10, 277-303.

[69] Robinson, P. (1995). Review article: Attention, memory, and the "noticing" hypothesis. Language Learning, 45, $283-331$.

[70] Roper, W. J. (1977). Feedback in computer assisted instruction. Programmed Learning and Educational Technology, 14(1), 43-49.

[71] Saito, H. (1994). Teachers' practices and students' preferences for feedback on second language writers: A case study of adult ESL learners. TESL Canada Journal, 11(2), 46-70.

[72] Schmidt, R. (1990). The role of consciousness in second language learning. Applied Linguistics, 11, 129-158.

[73] Schmidt, R. (1994). Deconstructing consciousness in search of useful definitions for applied linguistics. AIM Review, 11,11-26.

[74] Semke, H. (1984). The effects of the red pen. Foreign Language Annals, 17, 195- 202.

[75] Sengupta, S. (1998). Peer evaluation: "I am not the teacher" ELT Journal, 52(1), 19-26.

[76] Sheppard, K. (1992). Two feedback types: Do they make a difference? RELC Journal, 23, 103-110.

[77] Silva, T. (1991). Second language composition instruction: developments, issues, and directions in ESL. In B. Kroll (Ed.), Second language writing: Research insights for the classroom (pp. 11-23). Cambridge: Cambridge University Press.

[78] Silva, T. (1993). Toward an understanding of the distinct nature of L2 writing: The ESL research and its implications. TESOL Quarterly, 27, 657-677.

[79] Stanley, J. (1992). Coaching student writers to be effective peer evaluators. Journal of Second Language Writing, 1(3), $217-233$.

[80] Svartvik, J.(1973). Errata: Papers in Error Analysis. Lund, Sweden: CWK Gleerup. 
[81] Swain, M. (1985). Communicative competence: Some roles of comprehensible input and comprehensible output in its development. In S. Gass \& C. Madden (Eds.), Input in second language acquisition (pp. 235-253). Rowley, MA: Newbury House.

[82] Swain, M. (1995). Three functions of output in second language learning. In G. Cook \& B. Seidihofer (Eds.), Principle and practice in applied linguistics: Studies in honour of 1-I. G. Widdowson (pp. 125-144). Oxford: Oxford University Press.

[83] Swain M., \& Lapkin, S.(1995). Problems in output and the cognitive processes they generate: A step towards second language learning. Applied Linguistics, 16, 371- 391.

[84] Schwartz, F., \& White, K. (2000). Making sense of it all: Giving and getting online course feedback. In K. W. White \& B. H. Weight (Eds.), The online teaching guide: A handbook of attitudes, strategies, and techniques for the virtual classroom (pp. 57-72). Boston: Allyn \& Bacon.

[85] Symonds, P. M., \& Chase, D. H. (1929). Practice vs. motivation. Journal of Educational Psychology, 20(1),19-35.

[86] Thorndike, E. L. (1927). The law of effect. American Journal of Psychology, 39(1/4), 212-222.

[87] Truscott, J. (1996). The case against grammar correction in U writing classes. Language Learning, 46(2), 327-269.

[88] Tsui, A. B. M., \& Ng, M. (2000). Do secondary L2 writers benefit from peer comments? Journal of Second Language Writing, 9(2), 147-170.

[89] Tuzi, F. (2004). The impact of c-feedback on the revisions of L2 writers in an academic writing course. Computers and Composition, 21, 2 17-235.

[90] Villamil, O. S., \& Guerrero, M. C. M. de (1996). Peer revision in the L2 classroom: Social-cognitive activities, mediating strategies and aspects of social behavior. Journal of Second Language Writing, 5(1), 51-75.

[91] Vygotsky, L. S. (1978). Mind in society: The development of higher psychological processes. Cambridge, MA: Harvard University Press.

[92] Vygotsky, L. (1986). Thought and language (A. Kozulin, Trans. \& Ed.). Cambridge, MA: The MIT Press.

[93] Wertsch, J. V. (1979a). From social interaction to higher psychological processes: A clarification and application of Vygotsky's theory. Human Development, 22,1-22.

[94] Wertsch, J. V. (1979b). The regulation of human action and the given-new organization of private speech. In G. Zivin (ed), The development of self-regulation through private speech (pp. 79-98). New York: John Wiley \&Sons.

[95] Yarbo, R., \& Angevine, B. (1982). A comparison of traditional and cassette tape English composition grading methods. Research in the Teaching of English, 16, 394-396.

[96] Zamel, V. (1985). Responding to student writing. TESOL Quarterly, 19, 79-101.

[97] Zhang, S. (1995). Reexamining the affective advantage of peer feedback in the ESL writing class. Journal of Second Language Writing, 4(3), 209-222.

Hamdollah Ravand is a PhD candidate at University of Isfahan, Iran and an academic staff of Vali-Asr University of Rafsanjan where he teaches language testing, teaching methodology, essay writing, and oral translation.

Abbas Eslami Rasekh is an assistant professor of TEFL at University of Isfahan, Iran where he teaches syllabus design, sociolinguistics, and ESP. 